\title{
STRUCTURE-ANTIMICROBIAL PROPERTIES STUDY OF SOME DIBASIC PHENYLCARBAMIC ACID ESTERS
}

\begin{abstract}
Jozef Csöllei ${ }^{1}$, Ivan Malík ${ }^{2 *}$, Marián Bukovský ${ }^{3}$
1Dept. of Chemical Drugs, Faculty of Pharmacy, University of Veterinary and Pharmaceutical Sciences in Brno, Czech Republic 2Dept. of Pharmaceutical Chemistry, Faculty of Pharmacy, Comenius University in Bratislava, Slovak Republic ${ }^{3}$ Dept. of Cell and Molecular Biology of Drugs, Faculty of Pharmacy, Comenius University in Bratislava, Slovak Republic

Submitted: $13-10-2015$

Revised: 01-11-2015

Accepted: 22-12-2015

ABSTRACT

Due to worldwide phenomenon of microbial resistance to commonly used therapeutic agents, antibiotics and antifungals, dibasic di-/trimethylphenylcarbamic acid esters 1-3, a non-traditional series of potential antimicrobials, has been in vitro evaluated against chosen gram-positive (Staphylococcus aureus) and gram-negative (Escherichia coli) bacterial strains as well as against yeast (C. albicans) by the minimum inhibitory concentration (MIC) assay. Taking into consideration chemical structure of tested derivatives, the incorporation of more than one protonated atom of nitrogen into salt forming fragment positively influenced the activity against $E$. coli. On the contrary, the presence of one or more methyl groups instead of 3-alkoxy side chain attached to lipophilic aromatic moiety has not found to be favorable structural feature. In entire set of inspected compounds, the most promising results have been found for the compound 3, chemically 1-[3-piperidinium-1-yl-2-(\{[(2,4,6-trimethylphenyl)amino]carbonyl\}oxy)propyl]piperidinium dichloride, against $E$. coli with the $\mathrm{MIC}=1.56 \mathrm{mg} / \mathrm{mL}$.
\end{abstract}

${ }^{*}$ Corresponding author Ivan Malík

Email:

malikivan001@gmail.com
Key words: Dibasic phenylcarbamic acid esters, Escherichia coli, hydrogen bonding, lipophilicity

\section{INTRODUCTION}

The widespread use of antibiotics has resulted in the emergence of multidrug-resistant bacterial pathogens. The prevalence and rate of antimicrobial resistance among important gram-positive and gram-negative pathogens has been progressive and relentless. Ten years ago, concern centred on gram-positive bacteria, particularly methicillin (oxacillin)--resistant Staphylococcus aureus and vancomycin--resistant Enterococcus spp. Now, however, clinical microbiologists increasingly agree that multidrug-resistant gram-negative bacteria pose the greatest risk to public health. Classic agents used to treat these pathogens have become outdated. Of the few new drugs available, many have already become targets for bacterial mechanisms of resistance (Kanj and Kanafani, 2011; Li et al., 2015; Moran et al., 2006; Rodvold and McConeghy, 2014).

It has been reported that the use of local anaesthesia may interfere with microbial assessment of tissue samples or culture specimens taken from patients with local infection because of the anaesthetics antimicrobial action. Local anaesthetics (LAs) have been known to bind specifically to the cell membranes of bacteria and to alter their structure and fluidity, to disrupt membrane potential and to inhibit membrane-bound respiratory function (Collura and Letellier, 1990). Lidocaine (lidocainium chloride; Figure 1) is the most studied active agent which has been included in this pharmacotherapeutic class (Begec et al., 2007; Gocmen et al., 2008; Lu et al., 2014). In historical terms, there have been three definitive papers describing, in turn, the chemistry, pharmacology and clinical features of lidocaine - research of Löfgren and Lundquist (1946), Goldberg (1949) and Gordh (1949).

The compounds under current study $\mathbf{1}-\mathbf{3}$ have shown structural similarity to the molecule of lidocaine - a typical structural arrangement for LAs. Particularly, the substances 1-3 have contained (i) lipophilic alkyl substituted aromatic ring, polar carbamate moiety attached to (ii) branched hydrocarbon connecting chain 


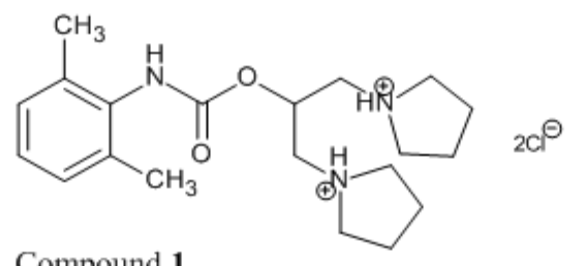

Compound 1

$\underbrace{\mathrm{CH}_{\mathrm{O}}}_{\mathrm{CH}_{3}}$

Lidocaine<smiles>Cc1cccc(C)c1NC(=O)OC(CNCCO)CNC1CCCCC1</smiles><smiles>CC(=O)OCC(CN1CCCCC1)OC(=O)Nc1c(C)cc(C)cc1C</smiles>

Figure 1. Chemical structure of lidocaine (lidocainium chloride) and dibasic esters of phenylcarbamic acid under the study

and (iii) salt forming fragment containing nitrogen(s) as well, as can be seen in figure 1.

The goal of current research was to in vitro investigate the efficiency of given alkylphenylcarbamic acid esters against gram-positive bacteria Staphylococcus aureus ATCC 6538 (Micrococcaceae), gram-negative bacteria Escherichia coli CNCTC 377/79 (Enterobacteriaceae) and yeast Candida albicans CCM 8186 as well and try to identify some structural features which could be beneficial in terms of their potency.

\section{MATERIALS AND METHODS \\ The compounds under the study}

The evaluated compounds $\mathbf{1}-\mathbf{3}$ (Figure 1), chemically 1-[3-pyrrolidinium-1-yl-2-(\{[(2,6-dimethylphenyl)amino]carbonyl \}oxy) propyl]pyrrolidinium dichloride (1), 1-[3-piperidinium-1-yl-2-(\{[(2,6-dimethylphenyl)amino $]$ carbonyl $\}$ oxy)propyl]piperidinium dichloride (2) and 1-[3-piperidinium-1-yl-2-(\{[(2,4,6-trimethylphenyl)amino]carbonyl oxy)propyl]piperidinium dichloride (3), were purchased from Department of Chemical Drugs, Faculty of Pharmacy, University of Veterinary and
Pharmaceutical Sciences in Brno, Czech Republic.

\section{The in vitro antimicrobial activity assay}

Microorganisms

Antimicrobial properties of tested molecules 1-3 were investigated against gram-positive bacteria S. aureus ATCC 6538 (Micrococcaceae), gram-negative bacteria E. coli CNCTC 377/79 (Enterobacteriaceae) and yeast $C$. albicans CCM 8186 as well. The tested bacterial strains were purchased from American Type Culture Collection (Manassas, United States of America) and Czech National Collection of Type Cultures (Prague, Czech Republic); yeast was obtained from Czech Collection of Microorganisms (Brno, Czech Republic).

\section{Culture media}

For a cultivation of the microorganisms, listed in the previous section of this paper, a blood agar, Endo agar and Sabouraud's agar (Imuna, Šarišské Michal'any, Slovak Republic) were used. Blood agar was prepared by adding $10 \%$ of defibrine sheep's blood to melted and cooled $\left(50^{\circ} \mathrm{C}\right)$ competent components. 
Determination of minimum inhibitory concentration (MIC)

The MIC readouts of the moleculs $\mathbf{1 - 3}$ were carried out by following the procedure previously published in literature (Csöllei et al., 2014).

The respective test compounds were dissolved in distilled water. Standard suspension of bacteria was prepared from their $24 \mathrm{~h}$ cultures which were cultivated on a blood agar (gram-positive bacteria) and endo agar (gram-negative bacteria). Standard suspension of Candida was prepared from its $48 \mathrm{~h}$ cultures cultivated on Sabouraud's agar.

Prepared suspension contained the concentration of $5 \times 10^{7}$ colony forming units (CFU) per $\mathrm{mL}$ of bacteria and $5 \times 10^{5} \mathrm{CFU} / \mathrm{mL}$ of Candida, respectively. The UV/VIS spectrophotometry was used for the determination of the microorganisms concentration. For the measurements, the UV/VIS range spectrophotometer Jenway, model 6305 (United Kingdom) was carried out. All evaluated suspensions were adjusted to the absorbance value of 0.35 at the wavelength of $540 \mathrm{~nm}$.

The suspension of the microorganisms was added in the amount of $5 \mu \mathrm{L}$ into the solutions of inspected compounds $(100 \mu \mathrm{L})$ and to double concentrated peptone broth medium (8\%) for bacteria or to Sabouraud's medium $(12 \%)$ for Candida. The peptone broth and Sabouraud's media were purchased from Imuna (Šarišské Michal'any, Slovak Republic).

Starting concentration of prepared stock solutions was $50.00 \mathrm{mg}$ of respective compound per $\mathrm{mL}$ of distilled water. These stock solutions $(5 \%)$ were then serially diluted by a half and final concentrations were $25.00,12.50,6.25$, $3.13,1.56$, and $0.78 \mathrm{mg} / \mathrm{mL}$, respectively.

\section{Quantitative screening}

The quantitative screening was performed using sterile 96-well plastic microtiter plates (with round-bottomed wells) with matching covers. Microorganisms were incubated in each well at $37^{\circ} \mathrm{C}$ for $24 \mathrm{~h}$. Upon completion of this process, the volume of $5 \mu \mathrm{L}$ of evaluated suspension has been taken from each well by using transferring tool and cultured on a blood agar (S. aureus), Endo agar (E. coli) or on Sabouraud's agar (C. albicans), respectively. Petri dishes were then incubated for $24 \mathrm{~h}$ at $37^{\circ} \mathrm{C}$.

The positive control using only an inoculation of microorganisms and the negative control of solvent were realized parallelly. The nutrient concentration remained stable in each well, only the concentration of inhibitory compound changed. All experiments were performed in triplicate.

The MIC was regarded as the lowest concentration of antimicrobial agent required to inhibit the visible growth of microorganism after incubation (Andrews, 2001). The MIC was dependent on the presence/absence of the culture on used solid media after the transfer of $5 \mu \mathrm{L}$ of suspension from each well. Estimated MIC readout was dependent on the presence/absence of the culture on used solid media after the transfer of $5 \mu \mathrm{L}$ of suspension from each well. The MICs are reported in Table $\mathrm{I}$ in $\mathrm{mg} / \mathrm{mL}$ units.

\section{RESULTS AND DISCUSSION}

Following chemical structure of currently in vitro screened compounds 1-3, their antimicrobial activity has been dependent on: (i) type, number and position of the substituents attached to phenyl ring in lipophilic part, (ii) type and number of protonatable basic centres in salt forming moiety. Possible impacts of given structural aspects were discussed in next sections of the paper.

Current preliminary results have outlined that all the investigated compounds have shown relatively improved activity against gram-negative bacteria when compared to their potency against the gram-positive one or anticandidacidal efficiency, as can be seen in table. I

Previous research of Csöllei et al. (2014) has indicated that incorporation of 2-alkoxyphenyl moiety (where alkoxy=butoxy to hexyloxy) instead of current 2,6-dimethylor 2,4,6-trimethylphenyl ones has led to inconclusive effect of thus molecules against given microorganisms. On the contrary, the substitution by alkoxy side chain at 3-position has meant notable increasing in the potency of such compounds. The authors have also proposed their possible mechanisms of action. 
Table I. The in vitro efficiency of inspected compounds $\mathbf{1}-\mathbf{3}$ against selected microorganisms

\begin{tabular}{cccc}
\hline \multirow{2}{*}{ Entry } & \multicolumn{3}{c}{ MIC $(\mathbf{m g} / \mathbf{m L})$} \\
\cline { 2 - 4 } & S. aureus & $\boldsymbol{E}$. coli & C. albicans \\
\hline $\mathbf{1}$ & 25.00 & 25.00 & 25.00 \\
$\mathbf{2}$ & 25.00 & 3.13 & 25.00 \\
$\mathbf{3}$ & 25.00 & 1.56 & 12.50 \\
\hline
\end{tabular}

The electronic nature, steric hindrance and lipohydrophilic properties have been believed to be important, in order to explain the function of substituents in position 2 and 6 or 2, 4 and 6, respectively (Figure 1). It has been reported that lidocaine has rapidly inhibited the generation of membrane potential in the inverted membrane vesicles of bacteria. It has been suggested that inhibition of membrane potential might contribute to the killing of bacteria, and that outer membrane changes might facilitate access to the inner membrane as a major target of killing (Garlid and Nakashima, 1983; Ohsuka et al., 1994).

Following chemical structures of the molecules under current study, it could be supposed that practically free rotation around the $\mathrm{C}_{\text {arom }}-\mathrm{N}$ bond (Figure 1) could be possible, as reported in previous research (Remko, 1989) which has dealt $a b$ initio and quantum-chemical PCILO investigations of tocainide, a structurally very similar molecule due to the presence of 2,6-dimethylphenylaminocarbonyl group. Experimental $\mathrm{X}$-ray values for the torsion angle $a$ in the salts of lidocaine (Hanson and Röhrl, 1972; Yoo et al., 1975) have been in the range of $64-71.5^{\circ}$. It could be also possible that, while keeping 2,6-dimethylphenyl moiety, relative position of nitrogen atoms of salt forming groups and „amidic" proton have been different (perhaps not quite optimal) compared to their arrangement in the molecule of lidocaine (Hanson and Banner, 1974).

Furthermore, in the structure of currently tested compounds $1-3$, the presence of more polar carbamoyloxy bond instead of the "classical“ anilide one has influenced possible linkage of the molecules into chains through $\mathrm{N}-\mathrm{H} \cdots \mathrm{O}$ bonding (Gowda et al, 2007). For comprehensiveness, no interaction between methyl groups and NH-moiety has been observed (Gowda et al., 2007; Gowda et al., 2008).
It could be assumed that isosteric replacement of anilide fragment, the presence of two centres of protonation - pyrrolidinium or piperidinium moieties simultaneously with the absence of highly lipophilic alkoxy group attached to phenyl ring, has led to more complicated internalization of inspected derivatives into bacterial outer membrane. Given factors have resulted in relatively higher values of MIC, as can be seen in Table I.

It was stated that the molecules $\mathbf{1 - 3}$ have been regarded as relatively promising against gram-negative E. coli. It could be supposed that pyrrolidinium or piperidinium groups would be the most eligible proton donors in specific (drug-receptor) interactions between exposed phosphoryl and carboxyl groups of highly negatively charged outer face of bacterial outer membrane (Csöllei et al., 2014). Due to the negative charge of phosphate or carboxylate, the hydrogen bond would be fairly strong. That bond type could potentially lead to conformational changes within membrane. It was also interesting taking into account the conformation in which hydrogen atom of the charged "amine" group has been to main backbone of the molecule. For instance, the activity of lidocaine-type molecules, which have contained saturated ring with amine $\mathrm{N}$ atom and substitution of a $\mathrm{C}_{\alpha}$ atom, have been dependent on thus position: trans position to the main backbone has been responsible for antiarrhythmic activity, while gauche conformation has promoted local anaesthetic action (Główka and Olczak, 1999; Główka et al., 2005).

Current results have revealed that increasing in the lipophilicity due to incorporation of six-membered piperidinium cycles (compounds 2 and 3 ) instead of the five-membered pyrrolidinium ones (1) has meant slight improvement in the activity (Table I). 


\section{CONCLUSION}

Assuming a maintenance of fundamental structural motif of dibasic phenylcarbamic acid esters, for notable efficacy of the se compounds against gram-positive and gram-negative bacteria, the presence of lipophilic alkoxy side chain, which has contained more than four carbon atoms, have been regarded as essential. Furthermore, given fragment should be attached to 3-position of phenyl ring. The replacement of thus chain for one or more methyl groups has led to pronounced decrease in the activity, despite structural similarity of these molecules with antimicrobially efficient lidocaine. The conformation in which hydrogen atom of the charged amine group has been to the main backbone could be considered essential.

\section{ACKNOWLEDGEMENTS}

The authors dearly thank the anonymous reviewers for their valuable comments and helpful revision suggestions.

\section{REFERENCES}

Andrews JM., 2001. Determination of minimum inhibitory concentration. J. Antimicrob. Chemother. 48 (Suppl. 1): 5-16.

Begec Z., Gulhas N., Toprak HI., Yetkin G., Kuzucu C., Ersoy, MO., 2007. Comparison of the antibacterial activity of lidocaine $1 \%$ versus alkalinized lidocaine in vitro. Curr. Ther. Res. 68: 242248.

Collura V., Letellier L., 1990. Mechanism of penetration and action of local anesthetics in Escherichia coli cells. Biochim. Biophys. Acta 1027: 238-244.

Csöllei J., Malík I., Bukovský M., Sedlárová E., 2014. Dibasic esters of ortho-/meta-alkoxyphenylcarbamic acid containing 1-dipropylamino-3-piperidinopropan-1-yl and their antimicrobial activity. Pol. J. Microbiol. 63: 231-236.

Garlid KD., Nakashima RA., 1983. Studies of the mechanism of uncoupling by amine local anesthetics. J. Biol. Chem. 258: 7974-7980.

Główka ML., Olczak A., 1999. Geometry of lidocaine-like molecules: 2. Crystal structures of 2-benzyl-2-(1-piperidinyl)-
-N-(2,6-dimethylphenyl) acetamide and its hydrochloride hemihydrate. J. Chem. Crystallogr. 29: 695-700.

Główka ML., Olczak A., Białasiewicz W., Kwapiszewski W., 2005. Geometry of lidocaine-like molecules: 3. Structure of a potent antiarrhythmic agent: 2-Methyl-2-(1-morpholinyl)- $N$-(2,6-dimethylphenyl) acetamide. Pol. J. Chem. 79: 1079-1085.

Gocmen JS., Buyukkocak U., Caglayan O., Aksoy, A., 2008. In vitro antibacterial effects of topical local anesthetics. J. Dermatol. Treat. 19: 351-353.

Goldberg L., 1949. Studies on local anaesthetics. Pharmacological properties of homologues and isomers of xylocain (alkyl aminoacyl derivatives). Acta Physiol. Scand. 18: 1-18.

Gordh T., 1949. Xylocain - a new local analgesic. Anaesthesia 4: 21.

Gowda BT., Foro S., Fuess H., 2007. N-(2,6-Dimethylphenyl)acetamide. Acta Cryst. E63: 3154.

Hanson AW., Banner DW., 1974. 2-Diethylamino-2', $6^{\prime}$-acetoxylidine (lidocaine). Acta Cryst. B30: 2486-2488.

Hanson AW., Röhrl M., 1972. The crystal structure of lidocaine hydrochloride monohydrate. Acta Cryst. B28: 35673571.

Kanj SS., Kanfani ZA., 2011. Current concepts in antimicrobial therapy against resistant gram-negative organisms: Extended-spectrum $\quad \beta$-lactamase-producing Enterobacteriaceae, carbapenem-resistant Enterobacteriaceae, and multidrug-resistant Pseudomonas aeruginosa. Mayo Clin. Proc. 86: 250-259.

Li X-Z., Plésiat P., Nikaido H., 2015. The challenge of efflux-mediated antibiotic resistance in gram-negative bacteria. Clin. Microbiol. Rev. 28: 337-418.

Löfgren N., Lundquist B., 1946. Studies on local anaesthetics. Svensk. Kem. Tidskr. 58: 206-217.

Lu Ch-W., Lin T-Y., Shieh J-S., Wang M-J., Chiu K-M., 2014. Antimicrobial effect of continuous lidocaine infusion in a Staphylococcus aureus-induced wound infection in a mouse model. Ann. Plast. Surg. 73: 598-601. 
Moran GJ., Krishnadasan A., Gorwitz RJ., Fosheim GE., McDougal LK., Carey RB., Talan DA., 2006. Methicillin-resistant $S$. aureus infections among patients in the emergency department. N. Engl. J. Med. 355: 666-674.

Ohsuka S., Ohta M., Masuda K., Arakawa Y., Kaneda T., Kato N., 1994. Lidocaine hydrochloride and acetylsalicylate kill bacteria by disrupting the bacterial membrane potential in different ways. Microbiol. Immunol. 38: 429-434.
Remko M., 1989. Ab initio and PCILO investigations of the antiarrhythmic tocainide, its cation and hydrochoride. Chem. Papers 43: 267-278.

Rodvold KA., McConeghy KW., 2014. Methicillin-resistant Staphylococcus aureus therapy: Past, present, and future. Clin. Infect. Dis. 58 (Suppl. 1): S20-S27.

Yoo CS., Abola E., Wood MK., Sax M., Pletcher J., 1975. The crystal structure of lidocaine bis- $p$-nitrophenylphosphate. Acta Cryst. B31: 1354-1360. 